Л. Н. Белотелова, П. А. Волошин, С. А. Оськин, М. А. Радугин, В. Н. Сергеев, В. Н. Хмара

\title{
ИССЛЕДОВАНИЕ ВЛИЯНИЯ
} АЭРОДИНАМИЧЕСКОЙ СХЕМЫ ПРОТОЧНОЙ ЧАСТИ ВИХРЕВОЙ СТУПЕНИ НА ЕЕ ЭФФЕКТИВНОСТЬ

Приведень результать экспериментального исследования высоконапорной вихревой ступени с новой аэродинамической схемой. Представлены рекомендации по геометрии ступени, позволяющие повысить ее эффективность.

\section{E-mail: vozduhoduvka@mail.ru}

Ключевые слова: вихревая ступень, рабочее колесо, рабочий канал, структура потерь, эффективность компрессора.

Вихревые машины - сравнительно новый тип турбомашин. Хотя начало их исследований относится к 1950-м годам, однако до настоящего времени накоплено недостаточно экспериментальных и опытных данных, позволяющих получить универсальную методику расчета и проектирования вихревых турбомашин. Область применения вихревых машин достаточно широкая, что обусловлено экологической чистотой подаваемого воздуха: отсутствием в нем масла и продуктов износа. По своим параметрам (производительность, давление) вихревые машины сходны с роторными машинами объемного типа (РУТ, ротационные, водокольцевые), но в отличие от них обладают преимуществами турбомашин: «сухая» проточная часть, простота конструкции, отсутствие трущихся и быстроизнашивающихся частей (единственный подвижный элемент - ротор, вращающийся в обычных подшипниках качения).

По сравнению с классическими типами турбомашин - центробежными и осевыми - вихревые машины в области малых расходов являются низкооборотными, что позволяет использовать простой привод без применения мультипликаторов. Кроме того, вихревые машины отличаются отсутствием помпажных режимов и возможностью получения высоких коэффициентов напора в одной ступени.

В основе принципа действия вихревой машины лежит наличие в рабочем канале пространственного спиралевидного потока с изменяющимся шагом спирали. Газ, двигаясь по спирали от входа в канал к выходу из него, многократно взаимодействует с лопатками рабочего колеса, участвуя в энергообмене.

Основным недостатком вихревых машин является сравнительно низкий КПД (до $35 \ldots 40$ \%), что обусловлено особенностями про- 
цесса сжатия в вихревой ступени, при котором имеют место как потери, традиционные для машин динамического действия (трение, местные сопротивления, ударные потери), так и потери, характерные для объемных машин (потери переноса, подогрева газа на входе). Опыт показывает, что рабочие характеристики ступени сильно зависят от типа проточной части, т. е. от аэродинамической схемы движения газа.

В МГТУ им. Н.Э. Баумана накоплен большой экспериментальный материал не только для различных типов проточных частей, но и для различной геометрии отдельных их типов, в частности для схемы с периферийно-боковым каналом и серповидными лопатками рабочего колеса. Полученные зависимости реализованы при создании серийно выпускаемых вихревых вакуум-компрессоров ВВК-1, ВВК-2, ВВК-4, ВНА-100 и ВВК-300. Основной задачей модернизации и улучшения конструкции вихревого компрессора является повышение эффективности его работы.

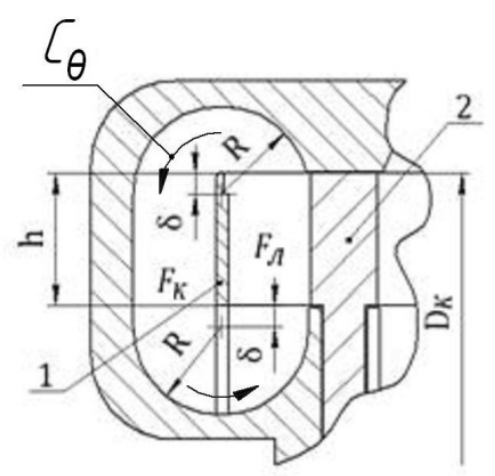

Рис. 1. Геометрические параметры канала компрессора:

1 - корпус компрессора; 2 - рабочее колесо
Снижение гидравлического сопротивления проточной части вихревой ступени. Придерживаясь регенеративной теории о наличии устойчивого вихря в канале компрессора, полагаем, что стабилизация меридиональной составляющей скорости $C_{\theta}$ вихревого потока в меридиональном сечении канала (рис. 1) приведет к повышению эффективности энергообмена лопаток рабочего колеса с газом в канале компрессора. В первом приближении рабочий процесс в ступени вихревого компрессора можно считать аналогичным процессу в центробежном компрессоре с многократной циркуляцией сжимаемого газа через рабочее колесо и неподвижные элементы ступени [2].

Геометрия меридионального сечения вихревой ступени определяет эффективность преобразования кинетической энергии движения газа в потенциальную энергию давления при каждом выходе потока из межлопаточного пространства рабочего колеса в канал корпуса. Согласно предложению И.М. Виршубского [2], один виток вихря можно рассматривать как взаимодействие газа с рабочим колесом в классической центробежной ступени (передача кинетической энергии от колеса к газу и ее дальнейшее преобразование в потенциальную энергию в канале). Основной задачей является преобразование кинетической энергии в потенциальную с минимальными потерями. 
Реализовать это возможно, в частности, изменив профиль меридионального сечения рабочего канала.

Продолжая аналогию с центробежной ступенью, можно проанализировать влияние геометрических параметров меридионального сечения канала (см. рис. 1) на меридиональную составляющую скорости $C_{\theta}$. Рассмотрим на примере конкретной аэродинамической схемы, как изменяется меридиональное сечение канала от выхода из рабочего колеса ко входу в него в пределах одного вихря. Геометрические параметры канала (см. рис. 1$)$ : диаметр рабочего колеса $D_{\text {к; }}$;

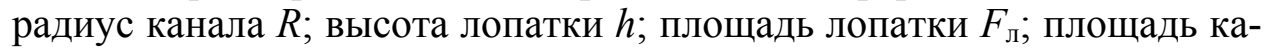

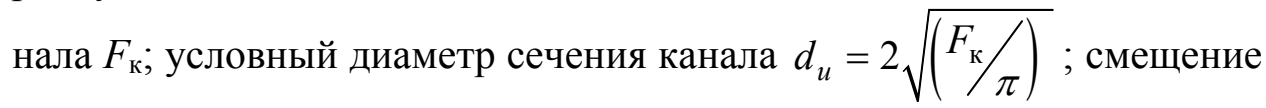
радиуса скругления канала $\delta$.

На рис. 2 приведены площади проходных сечений 1-6 на протяжении одного полного витка. Координаты каждой из этих площадей обозначены соответствующей цифрой. Координату в окружном направлении колеса примем за единицу. Простой расчет показывает, что на протяжении одного полного витка участки сечения с координатами площадей входа и выхода $F 1-F 2 ; F 2-F 3 ; F 3-F 4 ; F 4-F 5$; $F 5-F 6$ (см. рис. 2) оказываются попеременно конфузорными и диффузорными. Это негативно влияет на поток газа и увеличивает нестабильность $C_{\theta}$, т. е. увеличивает гидравлическое сопротивление.

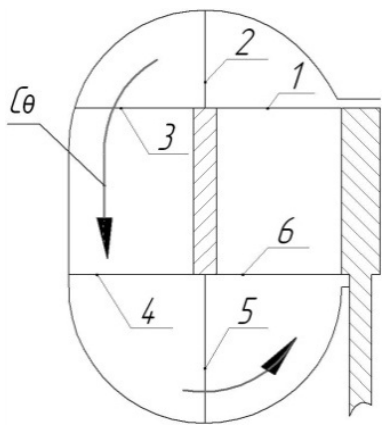

Рис. 2. Схема расположения проходных сечений

Для наглядности на рис. 3 приведен график, иллюстрирующий качественную картину течения на рассматриваемых участках траектории потока. Исходная проточная часть соответствует кривой 1 на рис. 3.

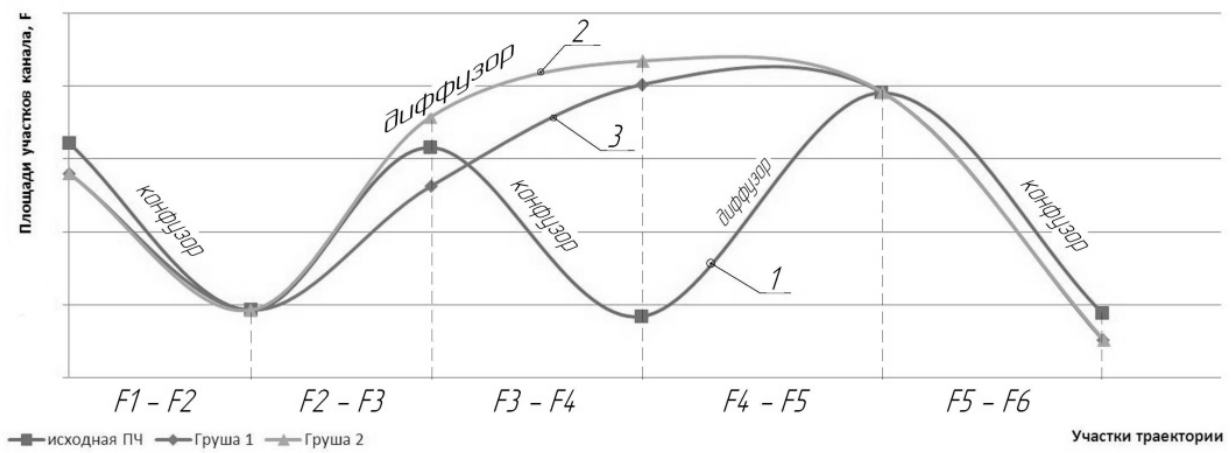

Рис. 3. Качественная картина изменения характера потока в меридиональном сечении канала 
Из сравнения картины течения в канале с центробежной ступенью можно сделать следующие выводы. Участок F1-F2 необходимо оставить конфузорным, поскольку это участок, аналогичен поворотному колену, которое проектируется с небольшой конфузорностью для создания более равномерного потока и уменьшения потерь [3]. По аналогичным соображениям следует оставить конфузорным и участок $F 5-F 6$, так как здесь необходимо разогнать поток перед входом на лопатки колеса. Что же касается остальных участков, то их следует сделать диффузорными. При этом для минимизации потерь принимается оптимальный угол раскрытия диффузора $\theta \approx 12^{\circ}$.

Из условия сохранения момента количества движения средний радиус действия циркуляционной составляющей скорости $C_{\theta}$ на поворотных участках сечения можно принять равным 3/4R [4], откуда можно вычислить длину поворотного участка. Таким образом, меридиональное сечение вихревой ступени (рис. 4) должно быть грушевидной формы.

Исходная пропочная 4acmb

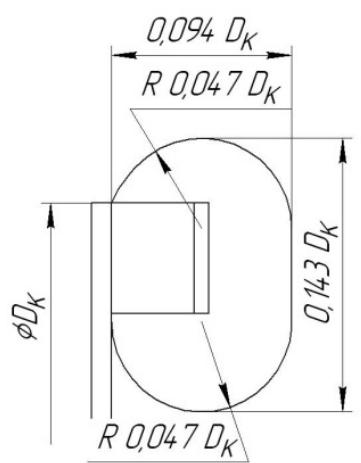

ГрушеВидная расточка канала корпyса - "Груша No1"

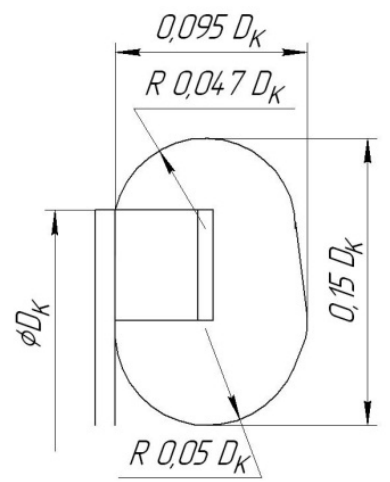

Грушевидная расточка канала корпуцса - "Груша No2"

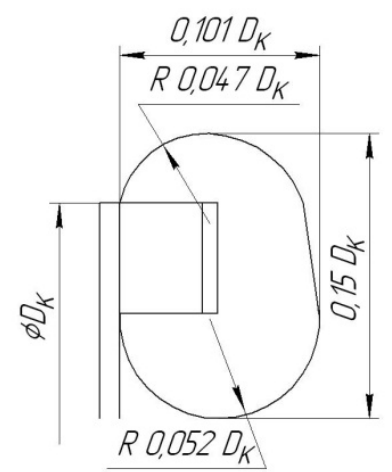

Рис. 4. Геометрические параметры меридиональных сечений каналов исследованных ступеней

Результаты экспериментальных исследований. Для получения экспериментальных характеристик проведены испытания на серийном вихревом нагнетателе ВВК-2М со следующими вариантами меридионального сечения:

- исходная геометрия меридионального сечения (см. рис. 1);

- увеличенное меридиональное сечение с расширением на участке F2-F5 (“Груша № 1");

- второй вариант грушевидного меридионального сечения “Груша № 2", увеличенного по сравнению с “Грушей № 1”.

Геометрия исследованных вариантов меридионального сечения представлена на рис. 4. Размеры приведены в относительных к диа-

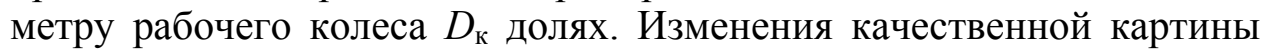


течения на участках $F 2-F 5$ канала для вновь спроектированных проточных частей иллюстрируют кривые 2 и 3 на рис. 3.

Характеристики вихревой ступени с соответствующим вариантом меридионального сечения представлены на рис. 5 в приведенных параметрах. Как следует из экспериментальных зависимостей на рис. 5, грушевидная форма меридионального сечения канала обеспечивает

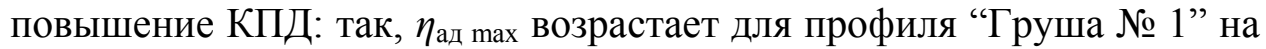
16 \% и для профиля “Груша № 2” на 9 \% по сравнению с исходным вариантом проточной части вихревой ступени.

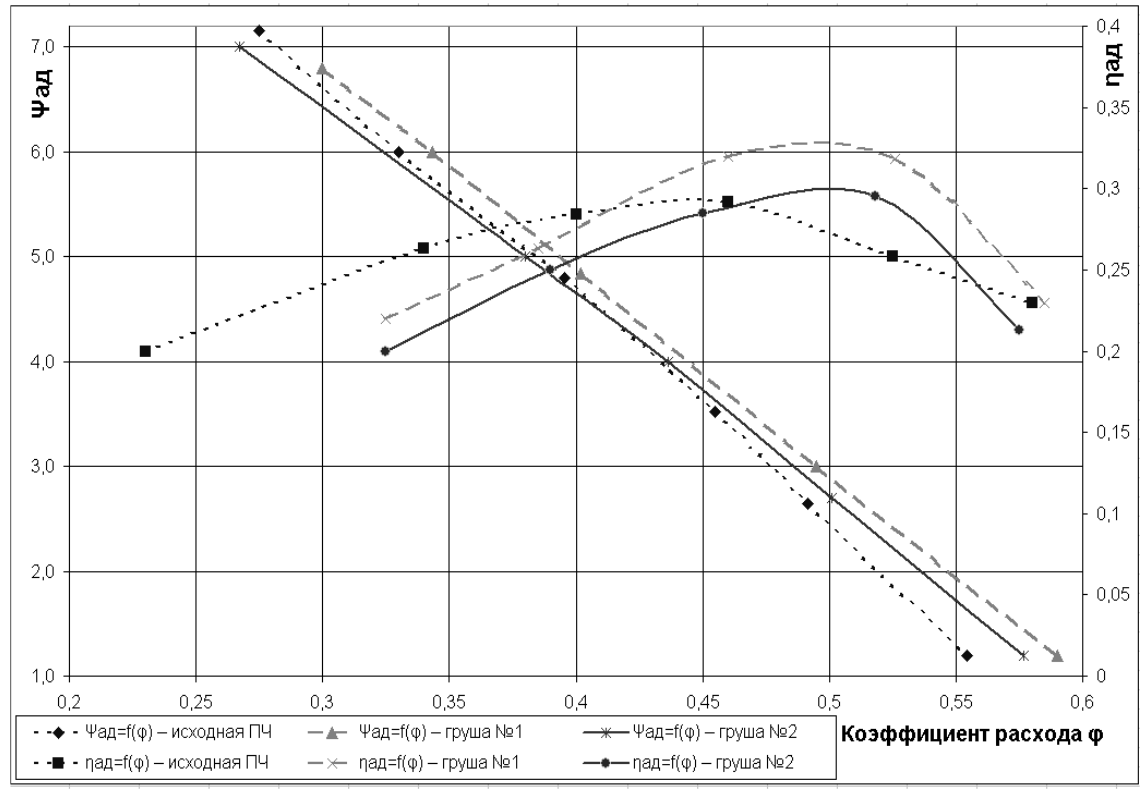

\section{Рис. 5. Влияние геометрии меридионального сечения канала на харак- теристики ступени}

Меньшее значение повышения КПД для профиля “Груша № 2" объясняется тем, что увеличение площади меридионального сечения канала (геометрия рабочего колеса остается постоянной) ведет к снижению коэффициента напора вследствие уменьшения интенсивности единичного взаимодействия газа с лопатками, обусловленного уменьшением относительной площади меридионального сечения лопаток рабочего колеса. Можно также отметить, что увеличение площади канала в меридиональном сечении при неизменном диаметре рабочего колеса приводит к повышению производительности ступени.

Таким образом, при переходе к грушевидному сечению увеличение КПД во всем диапазоне значений коэффициента расхода $\varphi$ (см. рис. 5)

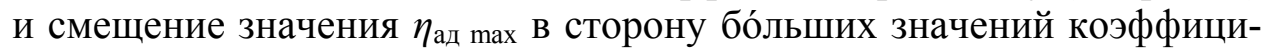
ента $\varphi$ обусловлено влиянием грушевидной формы меридионального сечения канала, обеспечивающей снижение гидравлических потерь в канале. 
В то же время увеличение площади канала в меридиональном сечении при неизменном диаметре рабочего колеса и грушевидной форме меридионального сечения обеспечивает повышение производительности ступени вихревого нагнетателя. Но с энергетической точки зрения чрезмерное расширение проточной части невыгодно, так как при этом несколько снижаются напор ступени и условный КПД вихревой машины (см. сравнение характеристик профилей “Груша № 1" и “"Груша № 2").

В ходе проведенных исследований установлено, что вариант меридионального сечения “Груша № 1" имеет наилучшие безразмерные характеристики. Это объясняется относительно небольшим значением $d_{u}$ и хорошей организацией потока в меридиональном сечении.

Использование рабочего канала вихревой турбомашины с грушевидным меридиональным сечением позволяет повысить эффективность вихревой ступени (наибольшее значение $\eta_{\text {ад }}=0,32$ для варианта профиля “Груша № 1”). Геометрия “груши” в относительных параметрах является оптимальной с точки зрения достижения максимальной эффективности вихревой ступени.

\section{СПИСОК ЛИТЕРАТУРЫ}

1. Исследование ступени вихревого нагнетателя с периферийно-боковым каналом и серповидными лопатками рабочего колеса / В.Н. Сергеев, В.Н. Хмара, Л.Н. Белотелова и др. // Вестник МГТУ им. Н.Э. Баумана. Сер. Машиностроение. - 2011. - С. 110-118.

2. В иршубский И. М., Рекстин Ф. С., Шквар А. Я. Вихревые компрессоры. - Л.: Машиностроение, 1988.

3. С е ле з н е в К. П., П о д о бу е в Ю. С., А н и с и м в С. А. Теория и расчет турбокомпрессоров. - Л.: Машиностроение, 1968.

4. Х м а а В. Н. Теория и расчет вихревых вакуумных компрессоров: учеб. пособие по курсу «Динамические машины» / под ред. П.И. Пластинина М.: МВТУ, 1988. - 44 c. 